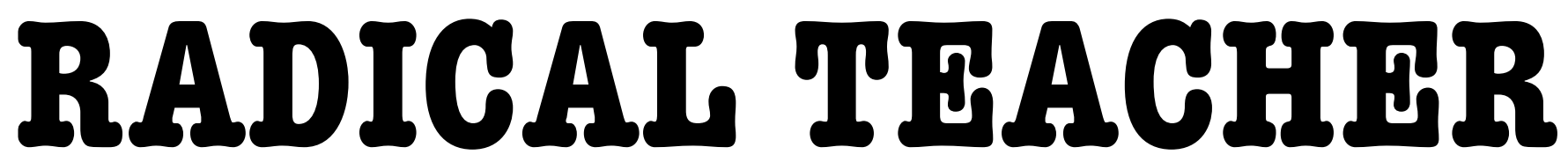

A SOCIALIST, FEMINIST, AND ANTI-RACIST JOURNAL ON THE THEORY AND PRACTICE OF TEACHING

\title{
Homophobia: A Weapon of Sexism
}

(RADICAL TEACHER NO.40, 1991)

by Carole Sheffield

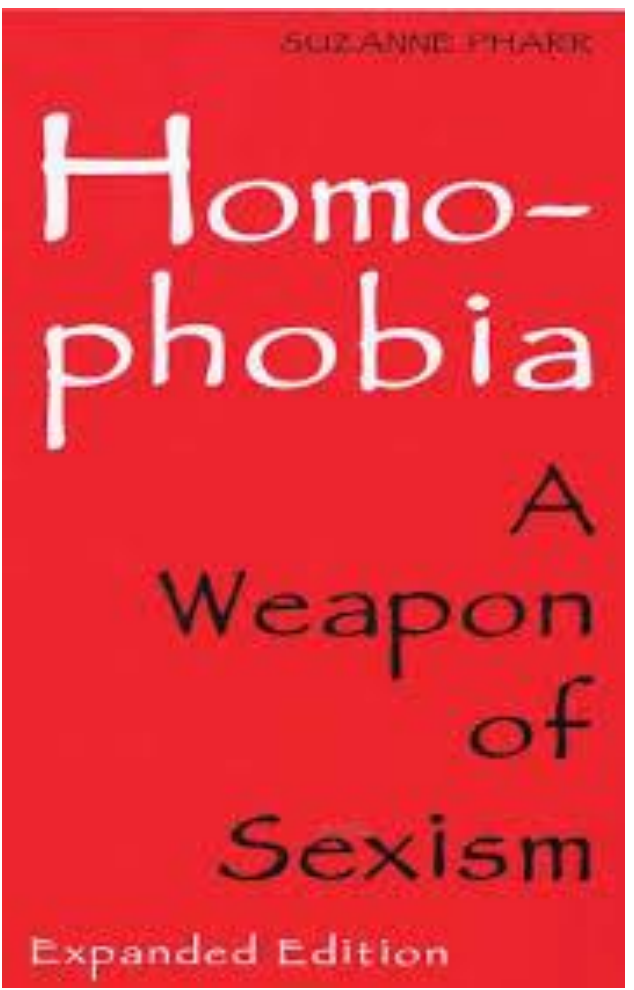

HOMOPHOBIA: A WEAPON OF SEXISM. SUZANNE PHARR. WOMEN'S PROJECT, 1988 
Homophobia: A Weapon of Sexism. Suzanne Pharr. Women's Project.

$\mathrm{I}$ $\mathrm{n}$ just ninety-one pages Suzanne Pharr manages to engage students in a very complex and deeply personal political struggle. That she does this without minimizing the scope of her argument is testimony to the power and the economy of her writing. Essentially her argument is that "sexism, that system by which women are kept subordinate to men, is kept in place by three powerful weapons designed to cause or threaten women with pain and loss ... the three are economics, violence, and homophobia." Students in my "Politics and Sex" course read this text after they have been studying the economics of oppression and sexual terrorism for several weeks, so they are somewhat prepared for the next step -- integrating the oppression of lesbian women and gay men into their understanding of racial and sexual domination. What they are not prepared for, however, is the extent to which Pharr draws them into her analysis.

One of the most powerful tools of oppression, inherent in each of the weapons of sexism discussed by Pharr, is privilege. Throughout the book, Pharr analyzes not only the dynamics of privilege and how it is constructed but also how it is reproduced by each one of us. Reading Pharr, male students, for example, both straight and gay, begin to come to terms with their participation in "lesbian-baiting" and how it is a manifestation of misogyny. When she describes the alienation and invisibility she felt in her early life as a lesbian -- "I showed the world only a small portion of who I was and even that portion was a lie" -- she leads non-lesbian women to examine the depths of their own oppression. They understand that they too have lived partial lives due to sexism and begin to wonder, enthusiastically, about further connections between themselves and their lesbian sisters. Lesbian students write how liberating it is -- often for the first time in a college environment dominated by heterosexuals -- to hear the word lesbian spoken repeatedly with acceptance and not with ridicule. Most of the students are impressed with the section on "strategies for eliminating homophobia" because it involves them; it offers them specific and realistic strategies which they can use in their own lives.

Pharr's personal as well as analytical voice is so authentic that students are able to suspend their homophobia and truly listen to an integrated analysis of oppression and injustice. They begin to see that lesbian and gay rights is not simply a "bedroom issue" as they had been taught to believe. Homophobia: A Weapon of Sexism succeeds in showing us "the truth of the inter-connectedness of all oppressions."

(cc) BY-NC-ND

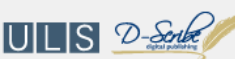

This work is licensed under a Creative Commons Attribution-Noncommercial-No Derivative Works 3.0 United States License.

This journal is published by the University Library System of the University of Pittsburgh as part of its D-Scribe Digital Publishing Program, and is cosponsored by the University of Pittsburgh Press.

\section{RADICAL TEACHER}

http://radicalteacher.library.pitt.edu
No. 113 (Winter 2019) 